\title{
Determination of the AGR-1 Capsule to FPMS Spectrometer Transport Volumes from Leadout Flow Test Data
}

J. K. Hartwell

J. B. Walter

D. M. Scates

M. W. Drigert

May 2007

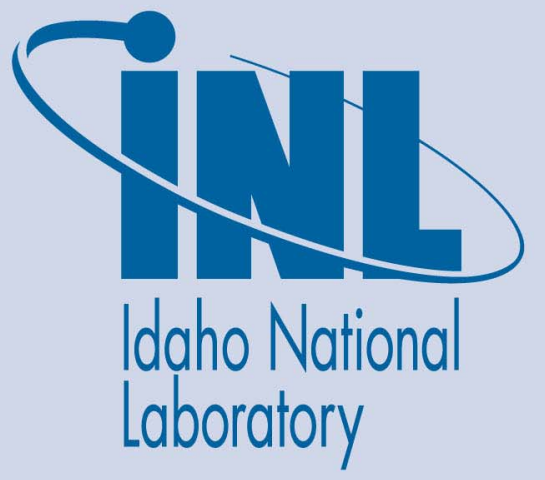

The INL is a U.S. Department of Energy National Laboratory operated by Battelle Energy Alliance 


\title{
Determination of the AGR-1 Capsule to FPMS Spectrometer Transport Volumes from Leadout Flow Test Data
}

\author{
J. K. Hartwell \\ J. B. Walter \\ D. M. Scates \\ M. W. Drigert
}

May 2007

\section{Idaho National Laboratory \\ Idaho Falls, Idaho 83415}

Prepared for the

U.S. Department of Energy

Office of Nuclear Energy

Under DOE Idaho Operations Office

Contract DE-AC07-05ID14517 


\title{
Determination of the AGR-1 Capsule to FPMS Spectrometer Transport Volumes From Leadout Flow Test Data
}

\author{
INL/EXT-07-12494
}

May 22007

Approved by

J. K. Hartwell (Author)

E. L. Reber (Peer Review)

D. A. Petti (Program)

\section{Date}

Date

Date 


\section{ABSTRACT}

The AGR-1 experiment is a fueled multiple-capsule irradiation experiment being conducted in the Advanced Test Reactor (ATR) in support of the Advanced Gas Reactor (AGR) Fuel Development and Qualification Program. A flow experiment conducted during the AGR-1 irradiation provided data that included the effect of flow rate changes on the decay of a short-lived radionuclide $\left({ }^{23} \mathrm{Ne}\right)$. This data has been analyzed to determine the capsule-specific downstream transport volume through which the capsule effluents must pass before arrival at the fission product monitoring system spectrometers. These resultant transport volumes when coupled with capsule outlet flow rates determine the transport times from capsule-to-detector. In this work an analysis protocol is developed and applied in order to determine capsule-specific transport volumes to precisions of better than $\pm 7 \%$. 


\section{CONTENTS}

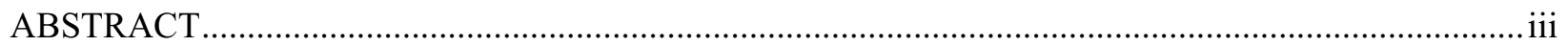



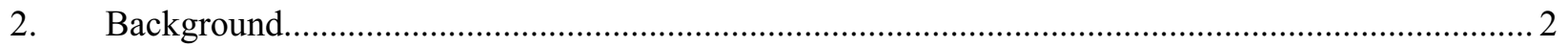

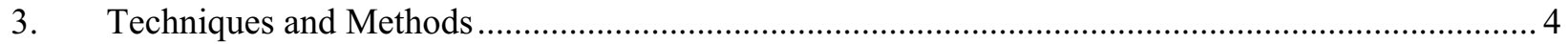

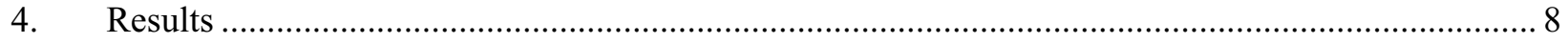

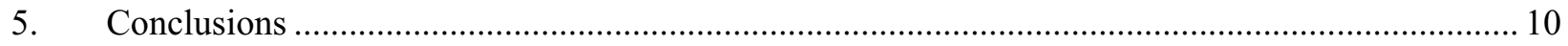

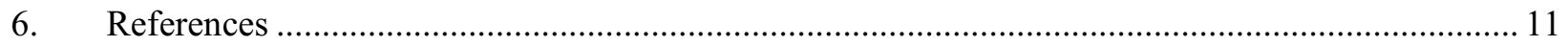

\section{FIGURES}

Figure 1 Simplified flow diagram of the AGR-1 effluent monitoring system ......................................... 2

Figure 2 Plot of the 23Ne activity measured at the G5 spectrometer (y axis) over the course of the leadout flow experiment. Each plotted activity is the result of a 20 minute acquisition time spectrum....... 4

Figure 3 Flow schematic for a single AGR-1 capsule to spectrometer sample volume............................ 5

Figure 4 Comparison of modeled activities (line) versus measured activities (points) for capsule 5 during the leadout purge experiment. The FPM(chi2) points $(\square)$ were those used in the fit since conditions were at steady-state for the duration of those measurements. The additional points $(\Delta)$ are simply shown for information, since flows changed somewhat during these measurements....... 8

\section{TABLES}

Table 1 Downstream transport volumes (Vt) for the AGR-1 test capsule effluents. 


\section{Introduction}

The AGR-1 experiment is a fueled multiple-capsule irradiation experiment being conducted in the Advanced Test Reactor (ATR) in support of the Advanced Gas Reactor (AGR) Fuel Development and Qualification Program. ${ }^{1}$ The experiment began irradiation in the ATR cycle that reached full power on December 26, 2006. The AGR-1 experiment will continue irradiation for about 2.5 years. Experiment design details have been published. ${ }^{2}$

The AGR-1 test train (the in-core portion of the experiment) incorporates six individual test capsules. Each capsule contains about 51,000 TRISO (TRIstructural ISOtopic) coated uranium oxicarbide fuel particles supported in a graphite matrix. Each capsule is continuously swept with an inert gas during irradiation. In intact fuel particles, the TRISO coating provides a barrier to fission product release. However, particles with failed TRISO coatings, either those that fail during irradiation or the tiny percentage of particles that are initially defective, can release fission products directly to the flowing gas stream. Because reactive fission products like the radioiodines and cesiums quickly deposit on test train and piping structures, the only released fission products that move downstream unattenuated are the noble fission gas isotopes of $\mathrm{Kr}$ and $\mathrm{Xe}$. One important measure of the fuel performance in these tests is quantification of the fission product releases over the duration of each irradiation experiment. To provide this important data for the inert fission gas releases, a Fission Product Monitoring System (FPMS) has been developed and implemented to monitor the individual capsule effluents for radioactive species. ${ }^{3}$

In order to derive certain fuel performance parameters (most significantly isotopic release-to-birth ratios) the fission gas data measured at the FPMS must be corrected for decay during the transport time from the constantly-irradiated fuel capsule to the FPMS measurement location. Since the capsule effluent gas flow rates change according to the desired experimental conditions, it is convenient to define a capsule-toFPMS transport volume that is a function of the hardware installation and then determine the desired transport time from this volume and the measured outlet flow rate. This work reports on an analysis of data, acquired during a test conducted for an entirely different purpose, which has allowed measurement of the AGR-1 capsule-to-FPMS spectrometer transport volumes. 


\section{Background}

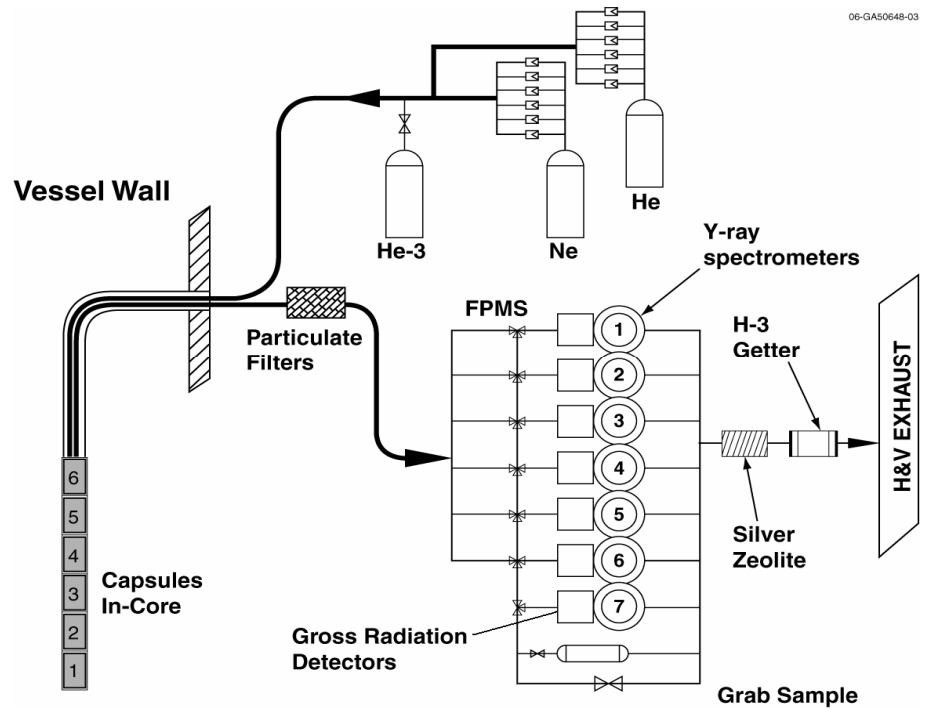

Figure 1 Simplified flow diagram of the AGR-1 effluent monitoring system
The AGR-1 experiment is an experiment presently under irradiation in the INL's Advanced Test Reactor (ATR). A simplified experiment flow diagram is presented in Figure 1. The FPMS is a collection of online gross radiation monitors and gamma-ray spectrometers that quantify radionuclide content of the test effluent from each of the six test capsules in the AGR-1 experiment. This system has been described elsewhere. ${ }^{3}$

Each spectrometer views a $58 \pm 2 \mathrm{~cm}^{3}$ volume of the gas

effluent from its associated test train capsule. Thus, each spectrum when analyzed provides the activity of fission gases in $58 \mathrm{~cm}^{3}$ of the flowing gas stream from the associated capsule. An important parameter needed to relate this effluent gas concentration data to fuel behavior characteristics is the decay correction that must be applied to the FPMS-measured activity data to correct the radioactive fission gases for their decay during transport to the measurement station. This decay correction is a function of the capsule outlet flow rate (measured by a flowmeter and recorded by the ATR data management system) and the effective volume through which the effluent must flow to reach its associated downstream FPMS measurement station. It is this capsule-specific effective downstream volume, termed here the "transport volume," that is determined in this work for each of the capsules.

To understand the basis of this work, and the reason for the test that generated the FPMS data, it is important to understand a feature of the AGR-1 test train and capsule design. The first important point is that the stack of six capsules is structurally enclosed by welding together their outer walls. Gas lines and instrument leads to the lower capsules in the test train must pass through the upper capsules. These leads and lines within the high temperature graphite portion of the capsules are contained within a stainless steel "thru tube" that delivers the required services to and from each individual capsule. The thru tubes extend from the top to the bottom closure plate of each capsule. In the plenum region between capsules there are no thru tubes so that required thermocouple and gas lines can be routed into and out of each capsule. The top of the in-core portion of the test train attaches to an "umbilical" cord called the leadout. The other end of the leadout bolts to a reactor vessel flange. Thus the leadout acts as a conduit for the various gas lines and leads to enter and exit the ATR reactor vessel.

Thermal expansion allowances required that while the thru tubes could be brazed or welded to the upper capsule heads, the lower closure plates had to be a tightly machined slip fit. This raised the potential for an undesirable capsule-to-capsule leakage path into the intercapsule plenums and thus through the leadout volume. Such leakage would compromise release data integrity. To ensure that capsule cross talk 
through the leadout volume did not occur, a helium (He) gas supply is provided to the leadout. The gas supply flow rate is adjustable and the leadout pressure is monitored. Since gas flows provided to the leadout must exit through the small slip-fit leakage path around the capsule thru tubes at their bottom closure plate, if the leadout flow rate is adjusted so that all capsules receive some inlet flow from the leadout, capsule cross talk can be eliminated.

In early March of 2007, while the AGR-1 experiment was being irradiated, a leadout flow experiment was conducted to determine what minimum leadout flow rate was required to eliminate capsule crosstalk. Three of the six capsules - Capsules 1, 2, and 5 - were deemed (based on pressure drop measurements conducted before test train installation) more likely to crosstalk than the other three, and the leadout flow experiment was performed on these three capsules.

The leadout flow experiment was conducted by setting the inlet flow conditions and holding them constant for an hour to assure equilibration before making each change. Initially, the flow to the leadout and each of the capsule inlets was He at $30 \mathrm{~cm}^{3} / \mathrm{min}$ at STP (termed "sccm"). Next, the inlet flow to one of the capsules to be tested was changed to $28 \mathrm{sccm}$ of He and $2 \mathrm{sccm}$ of Ne. Subsequently at 1 hour intervals the He flow to the leadout was decreased by $2 \mathrm{sccm}$. This was continued, decreasing the He flow to the leadout in a step-like fashion, until the leadout flow rate was at or near zero. After the leadout flow had been held at its minimum for one hour, the Ne flow to the tested capsule was secured, the flow to the leadout and the capsule returned to $30 \mathrm{sccm} \mathrm{He}$, repeating the initial conditions, and the system maintained at that condition for 1 hour. After the 1 hour purge and wait, the process of neon injection into the inlet and sequential decreases in the flow to the leadout was repeated for the next capsule to be tested.

During all of these leadout flow test periods, the AGR FPMS was acquiring sequential 20 minute spectra. In the capsule under test, the dominant detected species was ${ }^{23} \mathrm{Ne}$ (half life $37.24 \mathrm{sec}$ ), ${ }^{4}$ the neutron activation product of the ${ }^{22} \mathrm{Ne}$ supplied in the capsule inlet flow. To determine the lowest leadout flow that precluded effluent from the tested capsule from entering other capsule effluent lines, two pieces of data were of primary importance - the presence or absence of ${ }^{23} \mathrm{Ne}$ in the effluent from capsules that had no Ne supplied in their inlet stream (thus the activated Ne had to come from crosstalk with the capsule under test,) and the measured outlet flow from the tested capsule (an outlet flow rate lower than the inlet flow rate indicated losses to the leadout volume rather than inlet flow from the leadout volume.) From these leadout flow experiments we determined that a minimum leadout flow of $16 \mathrm{sccm}$ of $\mathrm{He}$ was required to eliminate capsule crosstalk.

However, an additional benefit of the leadout flow experiment is that it predictably and sequentially decreased each tested capsule's outlet flow rate while keeping the neon in the capsule inlet constant. This had the dominant effect of increasing the transport time to the FPMS spectrometers, which increased the decay time for the short-lived ${ }^{23} \mathrm{Ne}$, an effect that is exploited in this work to calculate the downstream transport volume from each capsule to its associated spectrometer. 


\section{Techniques and Methods}

The leadout flow experiment was conducted on capsules 1,2, and 5. A plot of the FPMS-measured activity of ${ }^{23} \mathrm{Ne}$ at detector G5 (monitoring the effluent stream of capsule 5) over the course of the leadout flow experiment on capsule 5 is presented in Figure 2. Each plotted point is the ${ }^{23} \mathrm{Ne}$ activity (in microCuries per $58 \mathrm{~cm}^{3}$ ) measured during a 20 minute spectral acquisition period. The effect of the increased decay time due to the sequentially decreasing outlet flow rate is reflected in the decreasing ${ }^{23} \mathrm{Ne}$ activity at the detector.

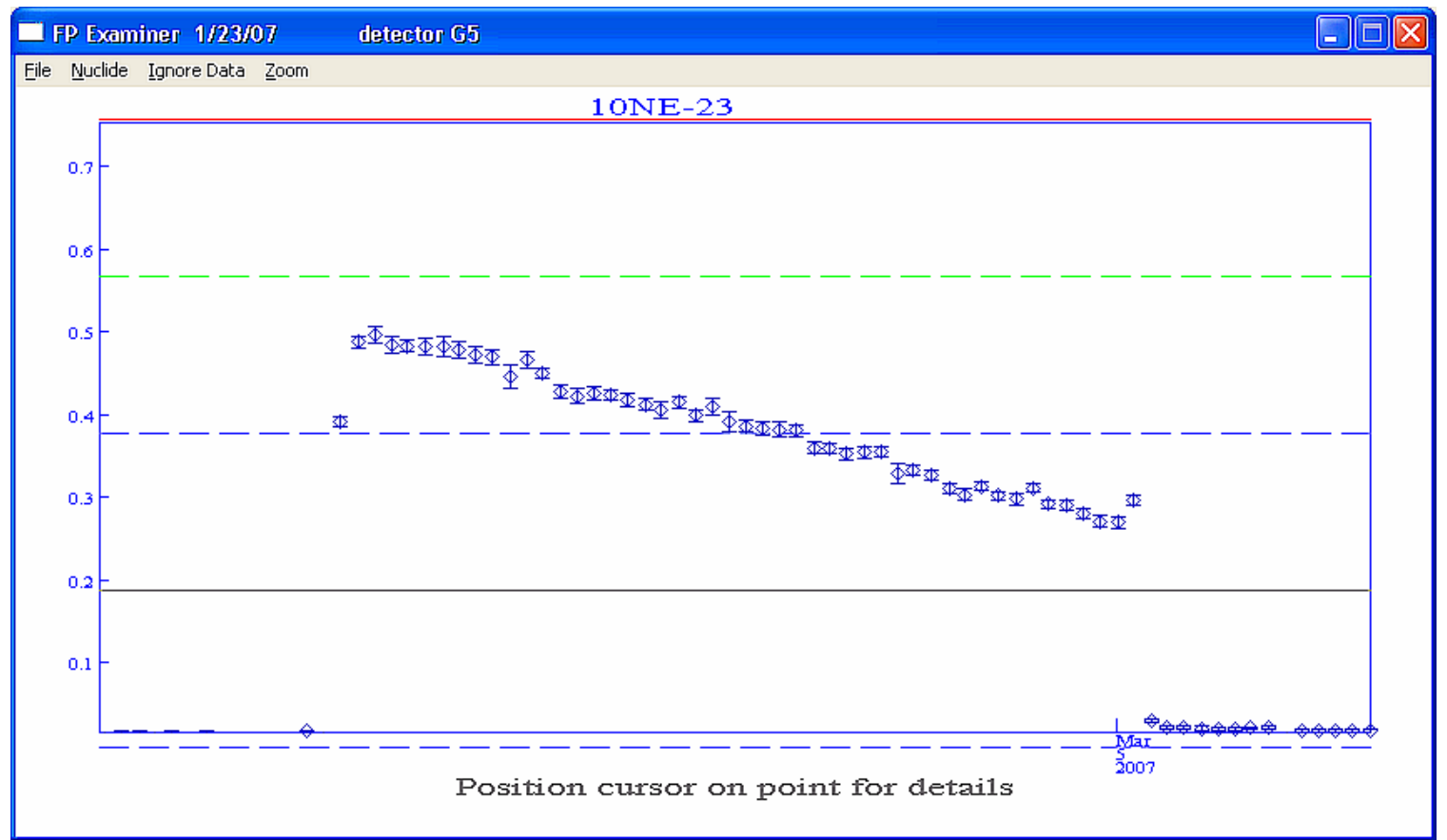

Figure 2 Plot of the $23 \mathrm{Ne}$ activity measured at the G5 spectrometer (y axis) over the course of the leadout flow experiment. Each plotted activity is the result of a 20 minute acquisition time spectrum.

With a constant capsule inlet of $2 \mathrm{sccm} \mathrm{Ne}$ and $28 \mathrm{sccm} \mathrm{He}$, decreasing capsule outlet flow rates (because of decreased $\mathrm{He}$ inflow from the leadout volume) has two significant effects on the activated ${ }^{23} \mathrm{Ne}$ measured at the downstream detector.

1. A decreasing capsule outlet flow increases the core residency time of the inlet $\mathrm{Ne}$, thus slightly increasing the concentration of ${ }^{23} \mathrm{Ne}$ produced per atom of inlet $\mathrm{Ne}$.

2. A decreasing outlet flow rate increases the transport time through the effective downstream volumes, which in turn decreases the downstream activity of the short-lived ${ }^{23} \mathrm{Ne}$.

The following methodology was developed to correct for the increased activation saturation factor and calculate downstream transport volumes for the AGR-1 capsules. 
Figure 3 presents a schematic of the flow parameters for a single capsule.

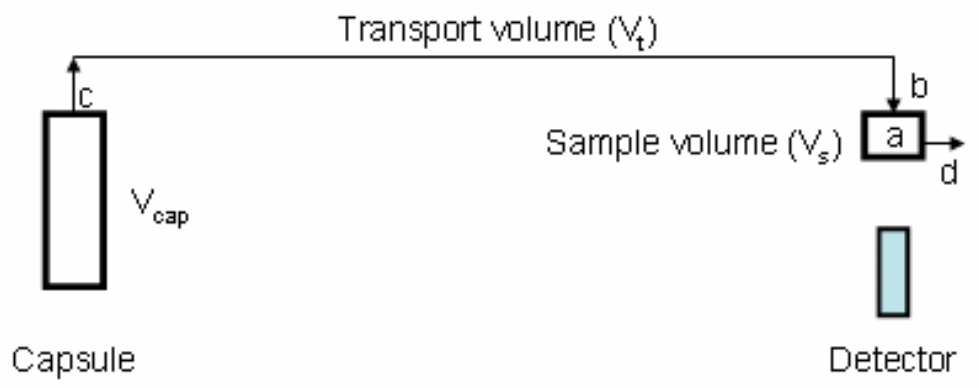

Figure 3 Flow schematic for a single AGR-1 capsule to spectrometer sample volume.

Since flow conditions during the leadout flow experiment were held constant for 1 hour while spectrometer counting periods were 20 minutes, conditions are steady-state. Thus, during a counting period RT starting at some time $t$, the on-line spectrometer measures the average number of radioactive ${ }^{23} \mathrm{Ne}$ atoms in the sample volume $\mathrm{V}_{\mathrm{s}}$. Since flows and activities are steady-state, no correction is required for the duration of the counting interval. Designating $\mathrm{R}_{\mathrm{i}}$ as the atoms/second of ${ }^{23} \mathrm{Ne}$ at point $\mathrm{i}$ in the schematic and similarly $\mathrm{N}_{\mathrm{a}}$ as the number of atoms in the sample volume, and designating the flow rate as $\dot{f}$, for the conditions in sample volume $\mathrm{V}_{\mathrm{s}}$ we can write:

$$
\begin{aligned}
& \frac{d N_{a}}{d t}=\text { Gain rate - Loss Rate } \\
& \frac{d N_{a}}{d t}=R_{b}-\left(R_{d}+\lambda * N_{a}\right)
\end{aligned}
$$

The average residency time of an atom in $\mathrm{V}_{\mathrm{s}}$ for flow rate $\dot{f}$ is $\mathrm{t}_{\mathrm{r}}=\frac{V_{s}}{\dot{f}}$, so we can write:

$$
\begin{aligned}
& \mathrm{R}_{\mathrm{d}}=R_{b} * e^{-\lambda * t} r_{\text {and: }} \\
& \frac{d N_{a}}{d t}=R_{b} *\left(1-e^{-\lambda * V_{s} / \dot{f}}\right)-\lambda * N_{a}
\end{aligned}
$$

However, at steady-state conditions, $\frac{d N_{a}}{d t}=0$, thus

$$
\lambda * N_{a}=R_{b} *\left(1-e^{-\lambda * V_{s} / \dot{f}}\right)
$$

and

$$
N_{a}=\frac{R_{b} *\left(1-e^{-\lambda * V_{s} / \dot{f}}\right)}{\lambda} .
$$


The number of ${ }^{23} \mathrm{Ne}$ atoms per second arriving at $\mathrm{b}$ is given as:

$$
R_{b}=R_{c} * e^{-\lambda * V_{t} / \dot{f}}
$$

The number of atoms per second at the capsule exit (c) is affected by increased or decreased gas flows to the capsule, since these decrease or increase the core residency time and thus affects the saturation factor for the activation of stable ${ }^{22} \mathrm{Ne}$ to ${ }^{23} \mathrm{Ne}$. Thus, the value for $\mathrm{R}_{\mathrm{c}}$ can be formulated as:

$$
R_{C}=K *\left(1-e^{-\lambda * V_{c a p} / \dot{f}}\right)
$$

The constant $\mathrm{K}$ is related to the neutronics of the activation reaction.

We can now write:

$$
N_{a}=K *\left(1-e^{-\lambda * V_{\text {cap }} / \dot{f}}\right) * e^{-\lambda *_{t} / \dot{f}} * \frac{\left(1-e^{-\lambda * V_{s} / \dot{f}}\right)}{\lambda}
$$

or in terms of the measured activity $\mathrm{A}_{\mathrm{a}}(\mathrm{Bq})$ :

$$
\begin{aligned}
& A_{a}=K *\left(1-e^{-\lambda * V_{\text {cap }} / \dot{f}}\right) * e^{-\lambda * V_{t} / \dot{f}} *\left(1-e^{-\lambda * V_{s} / \dot{f}}\right) \begin{array}{l}
\text { which can be solved for the } \\
\text { unknown transport volume } \mathrm{V}_{\mathrm{t}} \text { as: }
\end{array} \\
& V_{t}=\left[\frac{\dot{f}}{\lambda}\right] * \ln \left[\frac{K *\left(1-e^{-\lambda * V_{\text {cap }} / \dot{f}}\right) *\left(1-e^{-\lambda * V_{s} / \dot{f}}\right)}{A_{a}}\right] .
\end{aligned}
$$

The ATR data system logged the capsule outlet flow rates over the course of the leadout flow experiment. The outlet flowmeters were calibrated just prior to the leadout flow experiments, and their relative precision is believed to be about $\pm 1 \%$. Measured ${ }^{23} \mathrm{Ne}$ activities and their uncertainties $(\mathrm{Bq} \pm 1 \sigma)$ during the leadout flow experiment are available at 20 minute intervals from the FPMS spectral data analyses.

The viewed sample volume $\mathrm{V}_{\mathrm{S}}$ has been measured (by filling with water and weighing) and by calculation from the fabrication prints to have a volume of $58 \pm 2 \mathrm{~cm}^{3}$. Engineering estimates for the average capsule flow volume are $\mathrm{V}_{\text {cap }}=13 \pm 4 \mathrm{~cm}^{3}$. With these data and a guess at $\mathrm{K}$, downstream transport volumes were calculated at each time step during the leadout flow experiment on a capsule. The constant $\mathrm{K}$, which is related to the activation production parameters, was determined from a fit that minimized the variance in the values for $\mathrm{V}_{\mathrm{t}}$. The minimum variances obtained are consistent with the uncertainties in the measured activities, corresponding to a reduced $X^{2}$ of 1.03, 0.89 and 1.01 for the three analyzed capsules. 
The corresponding mean transport volumes are 126,138 , and $120 \mathrm{~cm}^{3}$ for capsules 1,2 , and 5 respectively.

The difference between a simple average and an inverse variance weighted average in each case was well under a percent, so in estimating the uncertainties we will continue with the simple average for simplicity. If the small uncertainty in the measured outlet flow rates is ignored, then the explicit equation for the uncertainties in the averaged $\mathrm{V}_{\mathrm{t}}$ results can be computed by normal error propagation techniques.

Thus:

$$
\left\langle V_{t}\right\rangle=\frac{1}{n} * \sum_{i} V_{t_{i}}=\frac{1}{n} * \sum_{i}\left[\ln \left(\frac{K}{A_{i}}\right)+\ln \left(1-e^{-\lambda * V_{\text {Cap }} / \dot{f}_{i}}\right)+\ln \left(1-e^{-\lambda * V_{S} / \dot{f}_{i}}\right)\right] * \frac{\dot{f}_{i}}{\lambda}
$$

The errors to be treated are uncorrelated. Thus:

$$
\begin{aligned}
& \sigma_{\left\langle V_{t}\right\rangle}^{2}=\left(\frac{\partial\left\langle V_{t}\right\rangle}{\partial V_{s}} * \sigma_{V_{S}}\right)^{2}+\left(\frac{\partial\left\langle V_{t}\right\rangle}{\partial V_{\text {cap }}} * \sigma_{V_{\text {cap }}}\right)^{2}+\sum_{i}\left(\frac{\partial\left\langle V_{t}\right\rangle}{\partial A_{i}} * \sigma_{A_{i}}\right)^{2} \\
& \frac{\partial\left\langle V_{t}\right\rangle}{\partial V_{s}}=\frac{1}{n} * \sum_{i}\left(e^{\lambda * V_{s} / \dot{f}_{i}}-1\right)^{-1} \text {, with a similar formulation for } \frac{\partial\left\langle V_{t}\right\rangle}{\partial V_{\text {cap }}} \text { and } \\
& \frac{\partial\left\langle V_{t}\right\rangle}{\partial A_{i}}=\frac{1}{n} * \frac{-\dot{f}_{i}}{\lambda * A_{i}}, \text { then: } \\
& \sigma_{\left\langle V_{t}\right\rangle}^{2}=\sigma_{V_{S}}^{2} *\left[\frac{1}{n} * \sum_{i}\left(e^{\lambda * V_{s} / \dot{f}_{i}}-1\right)^{-1}\right]^{2}+\sigma_{\text {Vcap }}^{2} *\left[\frac{1}{n} * \sum_{i}\left(e^{\lambda * V_{\text {cap }} / \dot{f}_{i}}-1\right)^{-1}\right]^{2}+\frac{1}{n} * \sum_{i}\left(\frac{\dot{f}_{i} * \sigma_{A_{i}}}{\lambda * A_{i}}\right)^{2}
\end{aligned}
$$

These calculations provide estimated variances of 42, 44, and 57 for capsules 1, 2, and 5 respectively. 


\section{4. $\quad$ Results}

The correlation of the measured activity data of capsule 5 with our modeled results over the course of the capsule 5 leadout flow experiment is shown in Figure 4. The model curve with 2 adjustable parameters agrees very well with the measured data. The total $X^{2}$ of the 16 FPM(chi) points, for which flow conditions should be stable, is 14.5 for a reduced $X^{2}$ of 1.03 . The reduced $X^{2}$ is marginally smaller at 1.01 and 0.89 respectively for capsules 1 and 2 .

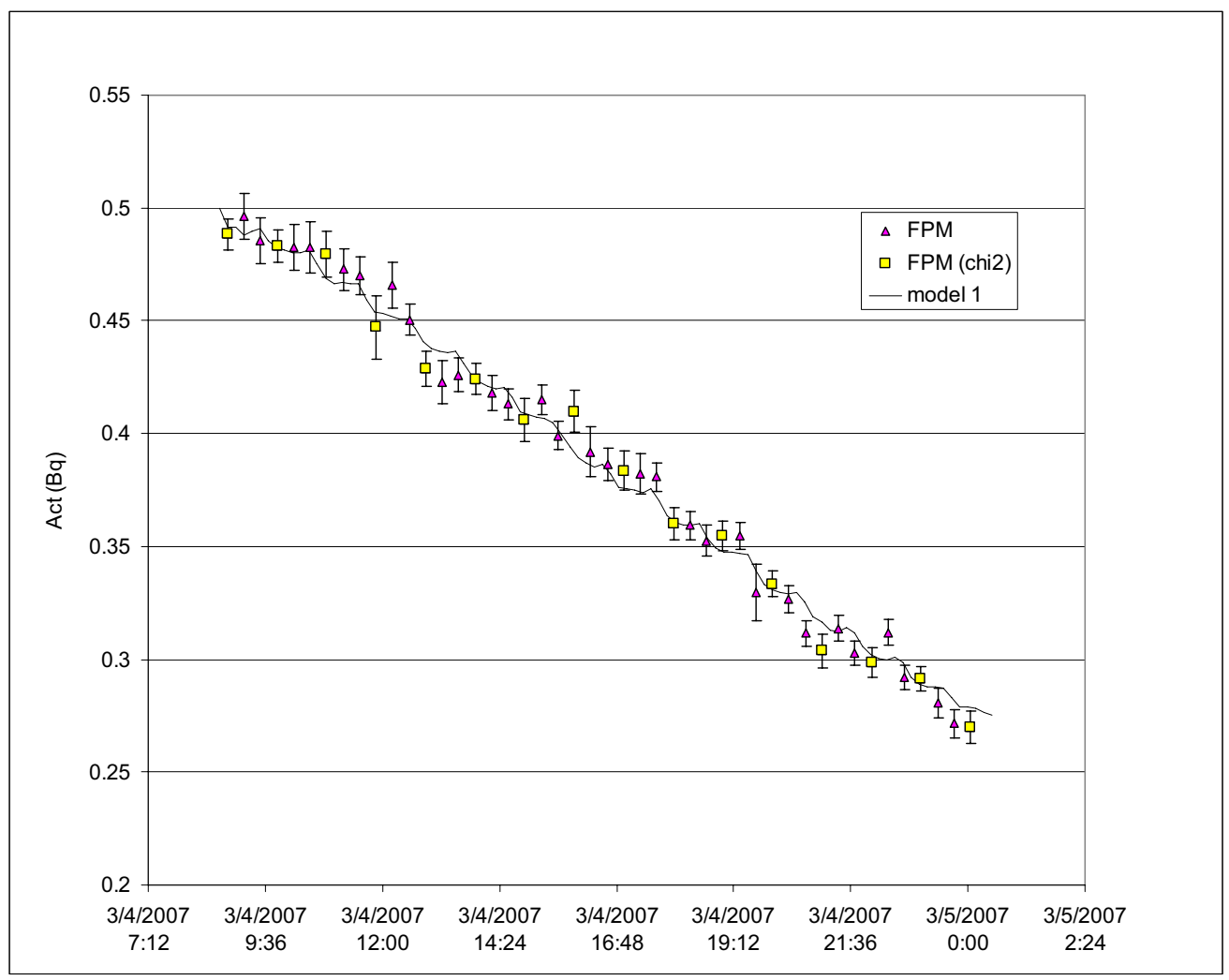

Figure 4 Comparison of modeled activities (line) versus measured activities (points) for capsule 5 during the leadout purge experiment. The FPM(chi2) points $(\square)$ were those used in the fit since conditions were at steady-state for the duration of those measurements. The additional points $(\Delta)$ are simply shown for information, since flows changed somewhat during these measurements.

Since the effluent lines from the 6 capsules are roughly the same, the transport volumes for capsules 3,4 , and 6 were assumed to belong to the same population as capsules 1,2, and 5. Thus, the calculated downstream flow volumes for capsules 3,4 , and 6 were determined by computing the variance-weighted average of the values for capsules 1,2, and 5 as determined in the previous section. Uncertainties on these values were computed as the population standard deviation, by multiplying the computed standard deviation of the average by $\sqrt{3}$ ( the number of values.) The results are presented in Table 1. Uncertainties are one standard deviation. 
TABLE 1 Downstream transport volumes (Vt) for the AGR-1 test capsule effluents

\begin{tabular}{cc}
\hline Capsule & $\begin{array}{c}\text { Transport Volume } \\
\left(\mathrm{cm}^{3}\right)\end{array}$ \\
\hline 1 & $126 \pm 7$ \\
2 & $138 \pm 7$ \\
3 & $128 \pm 9$ \\
4 & $128 \pm 9$ \\
5 & $120 \pm 8$ \\
6 & $128 \pm 9$ \\
\hline
\end{tabular}




\section{Conclusions}

The effective downstream transport volume through which the capsule effluents must pass during the AGR-1 fuel test irradiations is an important parameter for correction of the FPMS-measured fission gas release data, since this effective volume and the measured capsule outlet flow rates determine the decay correction to be applied to the measured activity data. The data from an experiment conducted for an entirely different purpose have been analyzed using the methodology derived in this work to calculate capsule-specific effective downstream flow volumes for the AGR-1 capsule effluents. These volumes have been determined with relative precisions of less than 7\%. At nominal outlet flow rates of $30 \mathrm{sccm}$ these volume uncertainties result in $1 \sigma$ uncertainties in the capsule-to-detector transport times of 3.5 to 4.5 seconds. 


\section{References}

1. Advanced Gas Reactor Team, M. A. Feltus, Program Manager, D. A. Petti, R. R. Hobbins, J. M. Kendall, and J. J. Saurwein, Editors, "Technical program plan for the Advanced Gas Reactor fuel development and qualification program," Idaho National Laboratory, Idaho Falls, ID, Tech. Rep. INL/EXT-05-00465 Revision 1, Aug. 2005.

2. S. B. Grover, "Completing the Design of the Advanced Gas Reactor Fuel Development and Qualification Experiments for Irradiation in the Advanced Test Reactor," INL Report INL/CON-0712136, presented at ICAPP 2007, the 2007 International Congress on Advances in Nuclear Power Plants, May 13-18, 2007, Nice Acropolis, France.

3. J. K. Hartwell, D. M. Scates, M. W. Drigert, and J. B. Walter, "Installation and Final Testing of an OnLine, Multi-Spectrometer Fission Product Monitoring System (FPMS) to Support Advanced Gas Reactor (AGR) Fuel Testing and Qualification in the Advanced Test Reactor," IEEE 2006 Nuclear Science Symposium Conference Record, Oct. 29 - Nov. 4, 2006, San Diego, CA.

4. R. B. Firestone, Table of Isotopes, $8^{\text {th }}$ Ed., V. S. Shirley, Editor, John Wiley \& Sons, NY, 1996. 